\title{
Design of experiments for determining the parameters affecting the behavior of the wheat straw adsorbent of hydrocarbons dispensed in water
}

\author{
C. Tsiodra ${ }^{1}$, K. Chatzizacharia ${ }^{1}$, S. Papadaki ${ }^{1}$, A. Bakolas ${ }^{1}$, \\ D. Economides ${ }^{1}$, D. Sidiras ${ }^{2} \&$ D. Hatziavramidis ${ }^{1}$ \\ ${ }^{1}$ School of Chemical Engineering, \\ National Technical University of Athens, Greece \\ ${ }^{2}$ Department of Industrial Management and Technology, \\ University of Piraeus, Greece
}

\begin{abstract}
Wheat straw, a lignocellulosic matter, with content up to $20 \%$ lignin on dry basis has been found to be an efficient adsorbent of hydrocarbons in water. In the present study the hydrocarbon absorptive capability of wheat straw that was previously treated with acid is investigated in oil spills which were created in the laboratory by dispersing diesel and crude oil in water. A 3-level Box-Behnken design of experiments has been executed in order to determine the parameters affecting the behavior of the acid-hydrolyzed wheat straw as an adsorbent, with design factors the maleic acid (MC4H4O4) concentration, and hydrolysis parameters temperature and reaction time. The absorbency of wheat straw is appraised by a combination of analytical methods such as Mercury Porosimetry (MP), Thermogravinetric Analysis (TGA), Total Organic Carbon (TOC) and Scanning Electron Microscope (SEM).

Keywords: wheat straw, oils spills, TGA, SEM, TOC, porosimetry.
\end{abstract}

\section{Introduction}

Spilled oil provokes severe environmental damages. The major problem with contaminated water is that it could not be used into municipal water supply either in industry or in agriculture [1]. The public concern for a healthy environment has led to new improved techniques and methods in order to deal with hazardous 
materials. In an effort to devise new methods for containment/mitigation of oil spills, we experimented with agricultural waste such as wheat straw, which is inexpensive, and readily available, low oil sorption capacity as well as low hydrophobicity [2].

Hydrocarbons are organic compounds of hydrogen and carbon, of different composition and chemical structure, classified in various groups, aromatic, alkanes, alkenes, cycloalkanes and alkynes. Most hydrocarbons are present in crude oil, where decomposed organic matter provides an abundance of carbon and hydrogen which can be bonded in various ways. Oil is one of the major resources of energy and commodity chemicals in the industrialized world at present. Chemical dispersion, in situ burning, mechanical containment and oil sorption by adsorbents are generally accepted clean-up methods to combat oil pollution [3].

In the present work, wheat straw, a lignocellulosic material, is studied for its use as an adsorbent of hydrocarbons in water [4]. Studies show that the surface energy of a lignin film is similar to that of cellulose, but the contact angle of water for lignin is higher than that for cellulose, i.e., lignin is more hydrophobic or less hydrophilic than cellulose. The lignin surface contains charged functional groups that may attract charged oil droplets.

Straw-like adsorbing materials are capable of holding oil as a result of two processes: adsorption and absorption. Wax coverage making the straw surface hydrophobic and capillary forces determine the efficiency of oil removal. The adsorption capacity depends primarily on the chemical structure of straw tissue that is in direct contact with oil and is a function of structure of straw stalks in bundles, distances between stalks, and cross-sections of each stalk and leaf. Due to high oil adsorption by straw, oil is mostly held by capillary forces on straw tissue and interior parts of stalk and by oil bridges between stalks. As a result, absorption of oil depends on the surface properties of straw.

In the present work, thermo-hydrolyzed wheat straw treated with maleic acid has been examined as hydrocarbon adsorbent. The efficiency of wheat straw as adsorbent is determined via several analytical methods, including TGA, TOC, SEM, and MP.

A 3-level Box-Behnken design was chosen, with three center points to check for curvature in the response surface. This is a type of response surface design that does not contain an embedded factorial or fractional factorial design. BoxBehnken designs have treatment combinations that are at the midpoints of the edges of the experimental space and require at least three factors. Factors can be categorical or arithmetic variables and can assume a limited number of possible values, known as factor levels, and are controlled in the experiment [5]. The factors and their levels chosen for this experiment are displayed in Table 1.

A Design of Experiments (DOE) approach was conducted in order to examine the effects of experimental conditions on the $\mathrm{pH}$ and Solid Residue Yield (SRY) of 15 samples. Those samples were examined for 5 different absorption environments such as crude oil, diesel, crude oil spill, diesel spill as well as water. Table 2 below presents all the results of the performed analytical methods of the treated wheat straw. Sample 5, after hydrolysis with Maleic acid $0.01 \mathrm{M}$, in $160^{\circ} \mathrm{C}$ at $0 \mathrm{~min}$, showed the best performance in all the performed analytical methods. 
Table 1: DOE critical factor and their levels.

\begin{tabular}{|l|c|c|c|c|}
\hline \multirow{2}{*}{ Factors } & \multicolumn{3}{|c|}{ Factor levels } & \multirow{2}{*}{ Units } \\
\cline { 2 - 4 } & -1 & 0 & 1 & \\
\hline $\mathrm{MC}_{4} \mathrm{H}_{4} \mathrm{O}_{4}$ Concentration, MC & 0.01 & 0.05 & 0.09 & $\mathrm{M}$ \\
\hline Temperature, Temp & 140 & 160 & 180 & ${ }^{\circ} \mathrm{C}$ \\
\hline Reaction time, $\mathrm{t}$ & 0 & 25 & 50 & min \\
\hline
\end{tabular}

Table 2: DOE table, experimental samples and results (porosity, TOC and TGA).

\begin{tabular}{|c|c|c|c|c|c|c|c|c|c|c|}
\hline Sample & MC & Temp & t & Weight & porosity & $\begin{array}{c}\text { Tot. } \\
\text { spec. } \\
\text { surface } \\
\text { area } \\
\left(\mathrm{m}^{2} / \mathrm{g}\right)\end{array}$ & $\begin{array}{c}\text { Butk } \\
\text { Density } \\
(\mathrm{g} / \mathrm{cm})\end{array}$ & $\begin{array}{c}\text { TOC } \\
(\%)\end{array}$ & TGA & $\begin{array}{c}\text { Peak } \\
\text { Temp. }\end{array}$ \\
\hline 1 & 0.09 & 140 & 25 & 4.20 & 77.844 & 13.347 & 0.266 & 29.19 & 72.65 & 320.73 \\
\hline 2 & 0.01 & 160 & 50 & 4.20 & 75.211 & 22.053 & 0.307 & 28.45 & 67.93 & 360.27 \\
\hline 3 & 0.09 & 180 & 25 & 4.05 & 67.755 & 17.814 & 0.342 & 24.12 & 65.50 & 312.60 \\
\hline 4 & 0.09 & 160 & 0 & 4.02 & 70.642 & 21.899 & 0.289 & 27.73 & 72.73 & 301.73 \\
\hline 5 & 0.01 & 160 & 0 & 4.30 & 76.748 & 32.500 & 0.317 & 41.43 & 87.35 & 349.04 \\
\hline 6 & 0.09 & 160 & 50 & 4.00 & 73.543 & 22.186 & 0.282 & 25.24 & 73.02 & 360.75 \\
\hline 7 & 0.05 & 180 & 0 & 4.18 & 71.57 & 19.122 & 0.317 & 25.98 & 73.27 & 318.45 \\
\hline 8 & 0.01 & 180 & 25 & 4.10 & 68.512 & 18.227 & 0.377 & 26.56 & 71.39 & 340.46 \\
\hline 9 & 0.05 & 140 & 50 & 4.10 & 78.784 & 22.263 & 0.257 & 29.43 & 74.70 & 356.29 \\
\hline 10 & 0.05 & 160 & 25 & 4.18 & 74.597 & 21.752 & 0.311 & 28.23 & 76.47 & 369.43 \\
\hline 11 & 0.05 & 180 & 50 & 4.10 & 70.948 & 17.379 & 0.361 & 23.06 & 71.95 & 344.38 \\
\hline 12 & 0.01 & 140 & 25 & 4.09 & 74.44 & 30.821 & 0.299 & 40.13 & 76.60 & 345.49 \\
\hline 13 & 0.05 & 160 & 25 & 4.18 & 73.832 & 20.246 & 0.274 & 36.34 & 71.06 & 315.38 \\
\hline 14 & 0.05 & 160 & 25 & 4.19 & 76.525 & 20.360 & 0.293 & 28.99 & 76.47 & 369.43 \\
\hline 15 & 0.05 & 140 & 0 & 3.80 & 81.158 & 25.622 & 0.260 & 28.22 & 75.43 & 356.61 \\
\hline
\end{tabular}

\section{Materials and methods}

\subsection{Wheat straw treatment method}

The material used was the wheat straw which was harvested in 2012, at the Kapareli village near the city of Thiva in the area of Kopaida in central Greece [6]. The acid hydrolysis process took place in a $3.75 \mathrm{~L}$ batch PARR 4843 . The optimum conditions for the hydrolysis process were presented in Table 1. The acid hydrolysis process performed at a liquid-to-solid radio of 20:1, which resulted in a $100 \mathrm{~g}$ of wheat straw added to a $2000 \mathrm{ml}$ volume of liquid [7].

\subsection{Modified wheat straw oil absorbance method}

In the modified wheat straw oil absorbance method, the ratio of water or oil absorbed to dry adsorbent weight was based on the ASTM F726-06 method. Following the standard method, 10PPM diesel produced by Hellenic Petroleum SA as well as crude oil was used. 


\subsection{Wheat straw analysis methods}

In previous studies, untreated and auto-hydrolyzed wheat straw were examined as hydrocarbon adsorbents with the use of several analytical method, such as MP, TGA, TOC, Fourier Transform Infrared Spectrometry (FTIR), X-Ray Diffraction Analysis (XRD), SEM, and Atomic Absorption Spectrometry (AAS). The first four were proved to be the most important for the following straw evaluation performance analysis [8].

\subsubsection{Total Organic Carbon (TOC)}

The treated, dried and milled wheat straw is mounted on metal stubs and is heated to $105^{\circ} \mathrm{C}$ in order to remove the moisture. The sample is placed in a crucible which is heated to $550^{\circ} \mathrm{C}$ for 2 hours [10]. The carbon content $(\% \mathrm{C})$ was calculated from the ash content ( $\%$ ash) using the following equation [11]:

$$
\% \mathrm{C}=((100-\% \text { ash }) * 100) / 1.8
$$

\subsubsection{Mercury porosimetry}

An idea of the adsorptive capacity of the modified wheat straw samples can be obtained with mercury porosimetry which detects meso- and macro-pore sizes $(2 \mathrm{~nm}-100 \mu \mathrm{m})$. Measurements were obtained using a Pascal 440 Porosimeter (Thermo Electron). Pressures between 0.01Torr and 200MPa can be developed which allows pores of $100 \mu \mathrm{m}$ to $3.75 \mathrm{~nm}$ radius to be measured. In order to obtain reproducible results, it was necessary to obtain good vacuum before filling the sample cell with mercury at 0.01 Torr for $30 \mathrm{~min}$ [9].

\subsubsection{Thermogravimetric Analysis (TGA)}

Thermogravimetric measurements were performed with a Mettler-Toledo TGA/DSC 1 HT Integrated Thermal Gravimetric Analyzer with high-purity nitrogen as a carrier gas and a flow rate of $40 \mathrm{~mL} / \mathrm{min}$. About $5-12 \mathrm{mg}$ samples were placed in an alumina pan of $70 \mu \mathrm{L}$ each time. The samples were heated from room temperature to $800^{\circ} \mathrm{C}$ at a heating rate of $10^{\circ} \mathrm{C} / \mathrm{min}$. The calculated thermogravimetic rate data were automatically recorded by the Integrated Thermal Gravimetric Analyzer system of Mettler-Toledo, using a STARe Thermal Analysis Software. The thermogravimetric experiment was used to obtain the parameters of chemical dynamics and the influence of any error was reduced as much as possible. The average size of all samples was below $0.5 \mathrm{~mm}$, so that the weight loss of the samples was controlled by reaction kinetics.

\subsubsection{Scanning Electron Microscopy (SEM)}

The morphology of the treated wheat straw fibers was determined from dried and milled samples, mounted on metal stubs, using a scanning electron microscope (SEM). Images were taken at $30 \mathrm{kV}$ by a FEI Quanta 200 microscope, with a LFD detector and magnifications that ranged from 300 to 4000 . 


\section{Results and discussion}

\subsection{Modified wheat straw analysis after oil absorbance measurements}

The analysis of raw modified wheat straw samples showed that some treatment combinations produced best results and these are considered as most appropriate to focus on for oil absorbance measurements. For example, attention can be drawn by samples 5 and 12 for further analysis (Table 2).

\subsubsection{Total Organic Carbon (TOC) results}

Table 3 shows the TOC content in acid hydrolysed wheat straw after exposure in different adsorbent environments such as crude oil, oil spill crude and diesel, diesel as well as water. More specifically, sample 5 with hydrolysis conditions maleic acid $0.01 \mathrm{M}, 160^{\circ} \mathrm{C}$ temperature and 0 minutes reaction time, show the highest TOC percentage. Moreover, sample 13 which is exposed to maleic acid at medium concentration $(0.05 \mathrm{M})$, resulted in $20.95 \%$ and $26.14 \%$ TOC.

Table 3: TOC results after hydrocarbon absorbence.

\begin{tabular}{|l|c|c|c|c|c|c|c|c|}
\hline Sample & MC & Temp & $t$ & $\begin{array}{c}\text { Crude } \\
\text { oil }\end{array}$ & $\begin{array}{c}\text { Oil } \\
\text { spill } \\
\text { diesel }\end{array}$ & Diese1 & $\begin{array}{c}\text { Oil } \\
\text { spill } \\
\text { Crude }\end{array}$ & Water \\
\hline 1 & 0.09 & 140 & 25 & 11.35 & 14.37 & 15.13 & 14.18 & 6.65 \\
\hline 2 & 0.01 & 160 & 50 & 10.05 & 14.24 & 12.51 & 13.01 & 6.92 \\
\hline 3 & 0.09 & 180 & 25 & 3.11 & 8.26 & 7.20 & 7.73 & 0.18 \\
\hline 4 & 0.09 & 160 & 0 & 3.34 & 12.77 & 11.53 & 13.29 & 5.30 \\
\hline 5 & 0.01 & 160 & 0 & 31.64 & 35.21 & 31.08 & 34.27 & 28.50 \\
\hline 6 & 0.09 & 160 & 50 & 3.32 & 10.46 & 5.82 & 6.27 & 1.67 \\
\hline 7 & 0.05 & 180 & 0 & 4.12 & 8.03 & 8.52 & 7.85 & 1.05 \\
\hline 8 & 0.01 & 180 & 25 & 4.67 & 9.73 & 6.64 & 6.43 & 1.93 \\
\hline 9 & 0.05 & 140 & 50 & 11.94 & 20.9 & 19.92 & 18.23 & 6.83 \\
\hline 10 & 0.05 & 160 & 25 & 7.92 & 14.13 & 9.81 & 11.78 & 5.00 \\
\hline 11 & 0.05 & 180 & 50 & 0.83 & 0.99 & 1.90 & 1.34 & 0.47 \\
\hline 12 & 0.01 & 140 & 25 & 29.74 & 32.52 & 31.61 & 30.96 & 28.45 \\
\hline 13 & 0.05 & 140 & 0 & 24.32 & 26.16 & 24.56 & 25.32 & 20.95 \\
\hline
\end{tabular}

Acid hydrolyzed wheat straw in oil spills of crude and diesel presents better results regarding TOC reduction (Figure 1). The initial TOC content in untreated wheat straw, which has been tested in previous study, was $51.7 \%$ [8]. Based on the current results, it should emphasized that TOC reduction is gradual, starting with acid-hydrolysed wheat straw as raw material and following with the samples after the absorbance of hydrocarbons.

\subsubsection{Mercury porosimetry results}

Figure 2 depicts the reduction of mercury porosimetry for modified wheat straw in sample 5 after five different kinds of hydrocarbon absorbents. The total porosity ranges from 19.49 to $73.41 \%$, according to the adsorbent conditions. The most important factor of those results is the reduction of \% porosimetry between the measurements before and after adsorption which was calculated between 57.25 


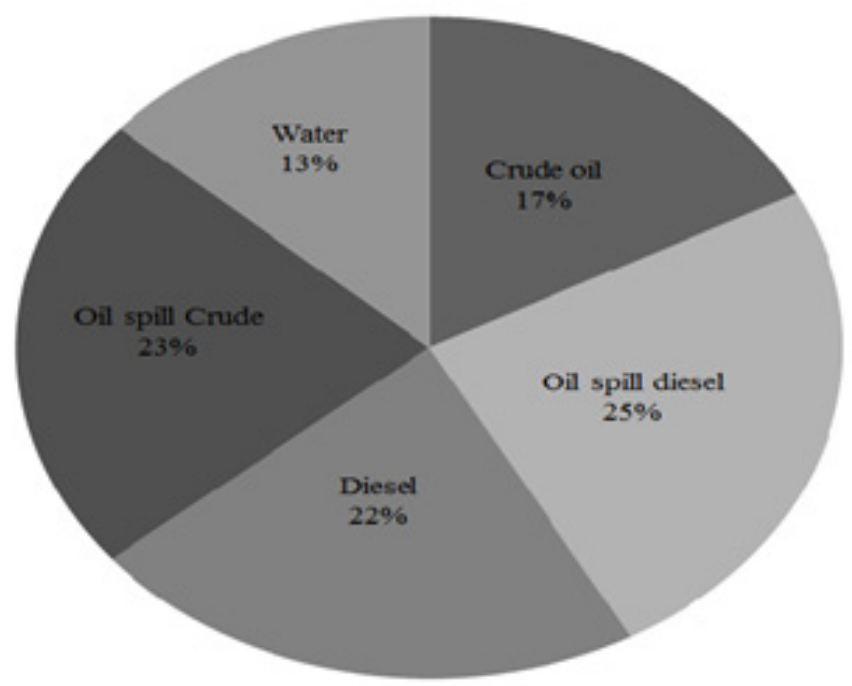

Figure 1: $\quad$ TOC average after hydrocarbon absorbency.

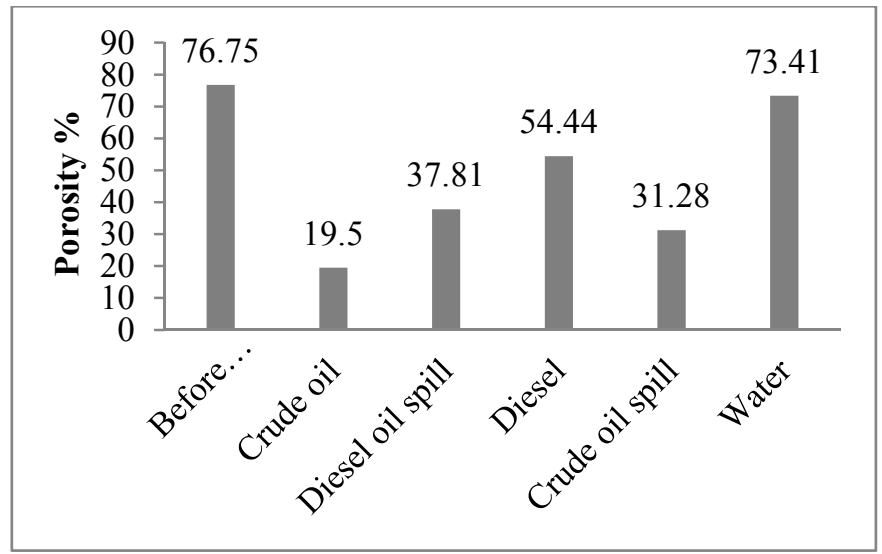

Figure 2: $\quad$ Reduction of $\%$ adsorbent porosity before and after absorbance.

and $3.34 \%$. The maximum porosimetry reduction is presented in crude oil as well as in oil spill crude oil, 57.25 and $45.47 \%$ respectively. It is worth highlighting that high porosimetry reduction is presented after the absorbance of oil spill diesel. Based on Table 4 it is assumed that the pore radius distribution varies significantly according to the mean that the adsorption took place. This fact depends on the size of the molecules that have been adsorbed from the adsorbent material indicating its selectivity. For instance it is obvious that the material shows selectivity to lighter hydrocarbons with small size molecules therefore the free pores that their radius is measured are the bigger ones. 
Table 4: Porosity and TOC results after hydrocarbons and water absorbance.

\begin{tabular}{|l|l|l|l|l|l|l|l|l|l|}
\hline MC & Temp & T & $\begin{array}{l}\text { Weight } \\
\text { (g) }\end{array}$ & $\begin{array}{l}\% \\
\text { porosity }\end{array}$ & $\begin{array}{l}\text { Average } \\
\text { pore } \\
\text { radius } \\
\text { (micron) }\end{array}$ & $\begin{array}{l}\text { Apparent } \\
\text { density } \\
\left(\mathrm{g} / \mathrm{cm}^{2}\right)\end{array}$ & TOC & $\begin{array}{l}\text { TOC } \\
\text { abs. }\end{array}$ & $\begin{array}{l}\text { Pore } \\
\text { reduction }\end{array}$ \\
\hline 0.01 & 160 & 0 & 4.30 & 76.75 & 0.483 & 1.36 & 41.43 & & \\
\hline 0.01 & 160 & 0 & $\begin{array}{l}\text { Crude } \\
\text { oil }\end{array}$ & 19.50 & 0.2112 & 1.01 & 41.43 & 31.64 & 57.25 \\
\hline 0.01 & 160 & 0 & $\begin{array}{l}\text { Oil } \\
\text { spill } \\
\text { diessi }\end{array}$ & 37.81 & 3.502 & 0.97 & 41.43 & 35.21 & 38.94 \\
\hline 0.01 & 160 & 0 & Diese1 & 54.44 & 0.994 & 1.08 & 41.43 & 31.08 & 22.31 \\
\hline 0.01 & 160 & 0 & $\begin{array}{l}\text { Oil } \\
\text { spill } \\
\text { crude }\end{array}$ & 31.28 & 4.567 & 0.99 & 41.43 & 34.27 & 45.47 \\
\hline 0.01 & 160 & 0 & water & 73.41 & 0.508 & 1.24 & 41.43 & 28.50 & 3.34 \\
\hline
\end{tabular}

\subsubsection{Thermogravimetric analysis (TGA)}

The pyrolysis profiles, in particular, demonstrate an increase in decomposition onset temperature, peak temperature and maximum rate of decomposition, indicative of a lower reactivity. The profiles are typical of lignocellulosic materials, showing the onset of an initial volatilization stage around $220^{\circ} \mathrm{C}$ followed by a char oxidation stage at higher temperatures. Sample 5 before the adsorption shows a mass loss of $87 \%$ in two stages. The first stage is at $350^{\circ} \mathrm{C}$ beginning at $250^{\circ} \mathrm{C}$ and indicating the decomposition of cellulose and hemicellulose. The second stage at $500^{\circ} \mathrm{C}$ is related to the decomposition of lignin. In case of adsorption of crude oil there is a significant increase in the total mass loss indicating the adsorption of crude oil. The great loss is shown at $350^{\circ} \mathrm{C}$ indicating the removal of cellulose and hemicellulose and heavy crude oil fractions. The mass loss begins from significant low temperatures around $80^{\circ} \mathrm{C}$ indicating the removal of lighter fractions under C5 such as naptha. Moreover there is a slight weight loss at $420^{\circ} \mathrm{C}$ indicating the removal of very heavy fractions $>\mathrm{C} 15$. The creation of chemical bonds between lignin and hydrocarbons enhance the lignin removal in lower temperatures. In case of diesel spill the mass loss starts at $70^{\circ} \mathrm{C}$ with light diesel fractions and maximizes at $350^{\circ} \mathrm{C}$ indicating the removal of cellulose, hemicellulose and heavy diesel fractions (C13). The adsorption in water matter increases the decomposition temperature of the treated straw (sample 13). This depends on the partial dilution of cellulose and hemicellulose in water that is trapped in a hydrophobic lignin base matrix that deteriorates the removal of sensitive thermo-degradable matter.

\subsubsection{Scanning Electron Microscopy (SEM)}

SEM images of hydrothermally pretreated in acidic environment wheat straw were obtained. In our previous study of untreated wheat straw, the straw is surrounded by a sheath leaf and at slightly higher magnification the individual cells of the straw wall can be identified. A high-resolution scan (of a primary cell wall lining the straw cavity shows interwoven cellulose microfibrils, partially imbedded in non-cellulosic polymers. In hydrothermally pretreated wheat straw, the defibrillating effect of the pretreatment causes the individual fibers to partially separate, as can be seen in SEM images. The pretreatment leaves a surface layer of debris and re-deposited cell-wall polymers on the individual fibers. 


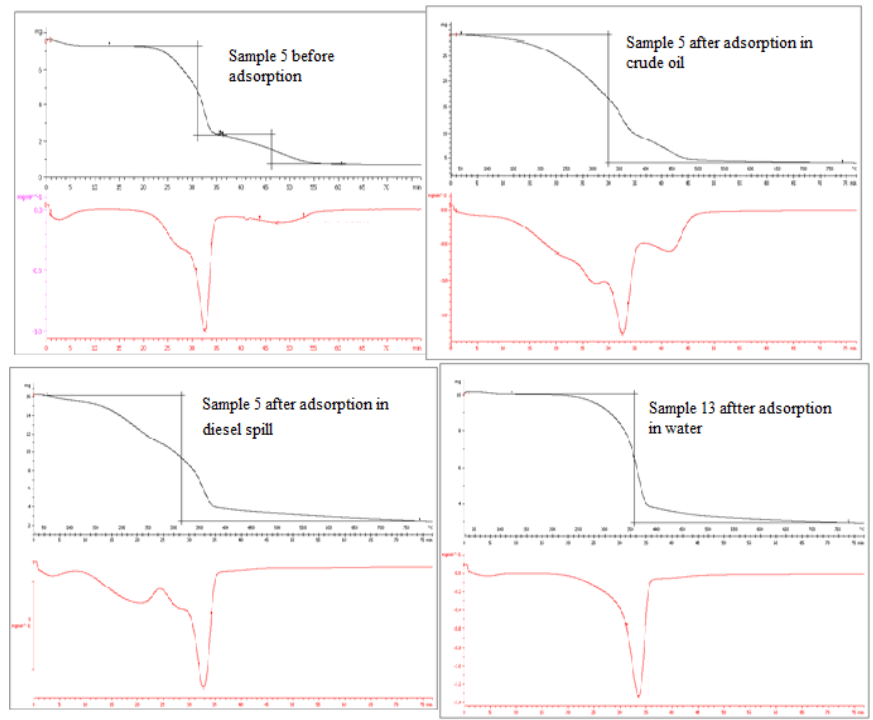

Figure 3: TGA results of sample 5.

The overall structure of the individual fibers seems to show large structural changes such as rupture of fibers or a visible increase of porosity, which are believed to be associated with thermal pretreatments. As it is observed in Figure 4 the differences between water and spill oils are clear. Holes and cracks were seen in the fibers indicating that the accessibility of the internal parts of the cell wall matrix had been improved due to structural dislocations. The primary and secondary cell walls appeared to be fully intact, except for the pits and simple perforations that already exist in certain cell types. Consequently, the effectiveness of pretreatment must be related to hemicellulose removal and lignin relocation. This is in spite of the fact that lignin is not removed by the pretreatment and that lignin is known to be responsible for hydrocarbon adsorbance.

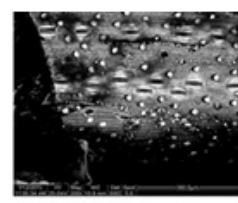

CRUDE OIL

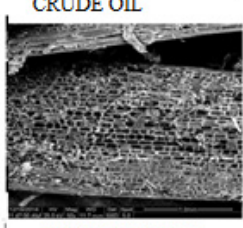

CRUDE OIL SPILL

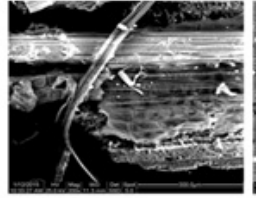

DIESEL OIL SPILL

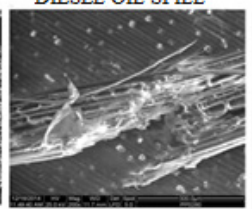

CRUDE OIL SPILL

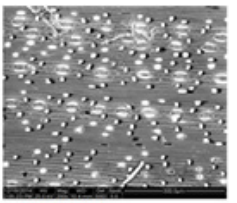

DIESEL

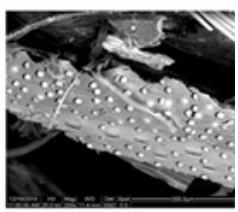

WATER

Figure 4: SEM results of sample 5. 


\section{Conclusions}

Lignocellulosic materials are superior to non-porous materials with regards to surface area. This advantage sets them as good candidates for sorption material. The oil absorptivity is based on interaction forces of Van der Walls type between oil and wheat straw. The sorption is based on the fact that both oil and wax are hydrocarbons, a fact that explains the physical interaction of oil through its irregular surface morphology [2]. Previous studies have shown that natural sorbents could be sufficiently used for oils spills removal more so than polypropylene materials that were used more often at the time [12]. This can be better explained by a combination of porosimetry results as well as TOC reduction. High porosity values which are shown to form the specimen of $0.01 \mathrm{M}$ Maleic acid, $160^{\circ} \mathrm{C}$ temperatures and $0 \mathrm{~min}$ reaction time, correspond to maximum TOC. Likewise, average porosimetry reduction after both acid hydrolysis and hydrocarbon adsorbents corresponds to average TOC reduction. Therefore, it is obvious that through acid hydrolysis we achieve high reduction of average porosimetry and TOC in wheat straw which has adsorbed crude oil and oil spills. This is also confirmed by SEM results.

\section{Acknowledgements}

This research has been co-financed by the European Union (European Social Fund - ESF) and Greek national funds through the Operational Program "Education and Lifelong Learning" of the National Strategic Reference Framework (NSRF). Research Funding Program: THALES. Investing in knowledge society through the European Social Fund. Project: THALIS - University Of Piraeus - Development of New Material from Waste Biomass for Hydrocarbons Adsorption in Aquatic Environments.

\section{References}

[1] Blumer, M. Oil on the sea. D.P. Hoult (ed.), Plenum Press, New York. NY. p. 6, 1969.

[2] Lee, B.G, Han, J.S., Rowell, R.M. Kenaf properties, processing and products. Ag \& Bio Engineering, Mississippi State, MS: Mississippi State University, pp. 423-433, 1999.

[3] Sidiras, D., Batzias, F., Siontorou, C., Bountri, A., Politi, D., Kopsidas, O., Konstantinou, I., Katsamas, G., Salapa, I., Zevropoulou, S., Factorial Experimental design for determining biomass thermochemical treatment and pure hydrocarbons adsorption parameters, 22nd European Biomass Conference and Exhibition, 2-23 June 2014, Hamburg Germany, pp. 10431057, 2014.

[4] Tolba, R., Wu, G. and Chen, A. Adsorption of dietary oils onto lignin for promising pharmaceutical and nutritional applications, Bioresources, 6 (2), pp. 1322-1335, 2011. 
[5] Shmidt, S. R., and R. G. Launsby, Understanding Industrial Designed Experiments, 2005.

[6] Apostolopoulos, G, Fardis, M., Chandrinou, C., Giannakopoulos, K., Kontos, A., Bidikoudi, M., Boukos, N., Falaras, P., Batzias, F., Sidiras, D. Surface characterization of unmodified/modified lignocellulosic biomas, before and after adsorption, 22nd European Conference and Exhibition, 2326 June 2014, Hamburg, Germany, pp. 1058-1070, 2014.

[7] Katsamas, G. and Sidiras, D. Sugars Production from Wheat Straw Using Maleic Acid. Regent Advances in Chemical Engineering, Biochemistry and Computational Chemistry. In Proc.4th European Conference of Chemical Engineering (ECCE '13) Paris, France, October 29-31, pp. 23-28, 2013.

[8] Chatzizaharia, K, S Papadaki, C Tsiodra, D Economides, D Sidiras, D Hatziavramidis, and E Dimitriou. "Hydrocarbons' Removal from Water Bodies Using Biobased Adsorbents". In 1st CIGR Inter-Regional Conference on Land and Water Challenges - Bari (Italy), 2013.

[9] Chesson, Andrew, Peter T Gardner, and Timothy J Wood, "Cell Wall Porosit Y and Available Surface Area of Wheat Straw and Wheat Grain Fractions." J Sci Food Agric (75): pp. 289-295, 1997.

[10] Feng, Y., X. Zhao, Y. Guo, G. Yang, J. Xi, and G. Ren. Changes in the Material Characteristics of Maize Straw during the Pretreatment Process of Methanation. Journal of Biomedicine and Biotechnology: 7, 2012.

[11] Haug, R.T. The Practical Handbook of Compost Engineering, Lewis Publishers, Boca Ratan, F.L., 1993.

[12] Adebajo, M O, R L Frost, J T Kloprogge, O Carmody, and S Kokot. Porous Materials for Oil Spill Cleanup : A Review of Synthesis: pp. 159-170, 2003. 